\title{
Causes of polymorphic melanism and its thermoregulatory function in a parasitoid wasp Meteorus pulchricornis (Hymenoptera: Braconidae)
}

\author{
Yosuke ABE, TAKuma NISHIMURA and KaORU MAETO* \\ Graduate School of Agricultural Science, Kobe University, Kobe, Hyogo 657-8501, Japan
}

Key words. Hymenoptera, Braconidae, Meteorus pulchricornis, parasitic wasp, body colour variation, thermal melanism hypothesis, reaction norm, solar radiation, body temperature, flight activity

\begin{abstract}
We investigated the variation in body colour and its thermoregulatory function in Meteorus pulchricornis (Wesmael) (Hymenoptera: Braconidae), a parasitoid wasp of Spodoptera and other free-living lepidopteran larvae. We show that the body colour of adult wasps darkens when cocoons are kept at low temperatures. The range in the variation in colour, however, differs for different parts of the body and among uniparental (thelytokous) strains. This melanism enables these wasps to attain a body temperature in sunshine up to $2^{\circ} \mathrm{C}$. Moreover, this small gain in body temperature can markedly increase the flight activity of wasps at low ambient temperatures. We conclude that the variation in body colour that resulted from rearing the cocoons at different temperatures enable the wasps to adapt to changing thermal environments. The ecological significance of the difference in the degree of melanism of the different strains is discussed.
\end{abstract}

\section{INTRODUCTION}

Melanism is the occurrence of darkly pigmented individuals, either as an intraspecific polymorphism or as a difference between species (True, 2003). Many hypotheses are proposed to account for the role of melanism, such as thermoregulation, cryptic colouration, aposematism, protection from UV radiation, pathogen resistance and sexual selection (True, 2003; Clusella-Trullas et al., 2007, 2008). Above all, the thermal melanism hypothesis (e.g. Watt, 1968; Kingsolver, 1987) posits that body colour is a significant factor affecting body temperature; i.e., dark coloured individuals can attain higher body temperatures than light coloured individuals when exposed to sunlight and thus dark coloured individuals may be better adapted to cold regions as they can be active for longer periods there, which is essential for feeding, mating or oviposition.

There are many studies that investigate the role of body colour in determining body temperature in polymorphically coloured insects. For example, in the two-spotted ladybird beetle, Adalia bipunctata (L.), which has melanic and non-melanic morphs, melanic beetles gained more heat from radiation and warmed up faster than nonmelanic individuals (Brakefield \& Willmer, 1985). In Tetrix subulata (L.), a pygmy grasshopper, which is polymorphic for body colour (black, striped, brown and white), black individuals reached a higher temperature excess than the other colour morphs (Forsman, 1997). Furthermore, some studies indicate that activity in insects is affected by body colouration. In $A$. bipunctata, melanics are more active than non-melanic individuals when exposed to the radiation from artificial sources of light (De Jong et al., 1996) and field research also indi- cates that melanic adults tend to emerge, mate, oviposit, and die earlier than non-melanic adults (Brakefield, 1984). In the speckled wood butterfly, Pararge aegeria (L.), the wing colour of the male determines the temperature of its thorax and mating strategy (Van Dyck \& Matthysen, 1998). In addition, some multivoltine insects exhibit a seasonal change in body colour, which seems to contribute to thermoregulation (Kingsolver, 1995; Van Dyck \& Wiklund, 2002). Although there are many studies that support the adaptive significance of thermal melanism in insects (Clusella-Trullas et al., 2007), the role of melanism in thermoregulation in parasitoids has yet to be elucidated. According to the physical model of Stevenson $(1985 \mathrm{a}, \mathrm{b})$, solar radiation and variation in body colour should have a smaller effect on the body temperatures of small insects weighing less than $10 \mathrm{mg}$, such as many parasitoid wasps, than of large insects, due to their more rapid loss of heat.

A better understanding of the effects of body colour on the thermoregulation and activity of natural enemies is important for successful biological control and the effects of ambient temperature on flight activity (Barbosa \& Frongillo Jr., 1977; Cox et al., 2007) and adult longevity (Thireau \& Regniere, 1995) have been investigated in parasitoid wasps. It is well-known that some parasitoid wasps show a temperature dependent phenotypic variation in body colour (Genieys, 1925; Narayanan et al., 1954; Shu-Sheng \& Carver, 1982; Quicke, 1997; Bernardo et al., 2007), which might indicate that the colour of the body could be important in thermoregulation. However, there are no studies that link temperature induced changes in body colour with the performance of parasitoid wasps.

\footnotetext{
* Corresponding author; e-mail: maeto@kobe-u.ac.jp
} 
In this study, we investigated the variation in body colour and its thermoregulatory function in adults of the wasp Meteorus pulchricornis (Wesmael) (Hymenoptera: Braconidae), whose larval stage is a koinobiont endoparasitoid of Spodoptera and other free-living lepidopteran larvae (Huddleston, 1980; Maeto, 1989; Takashino et al., 1998; Berry \& Walker, 2004; Liu \& Li, 2006; Yamamoto et al., 2009). There are both biparental (arrhenotokous) and uniparental (thelytokous) strains of this wasp (Fuester et al., 1993) and the body colour of uniparental strains varies from almost totally brownish yellow to mostly black (as shown below). Thus, this wasp provides a good model for studying thermal melanism in parasitoid wasps.

First, we determined the genetic (inter-strain) and ambient thermal factors that under lie the variations in body colour, using several uniparental strains of $\mathrm{M}$. pulchricornis. Next, we compared the increase in body temperature in sunshine of the darkest and lightest forms. Finally, we estimated the effect of increased temperature on the flight activity of adults in the laboratory.

\section{MATERIAL AND METHODS}

\section{Study insects}

Four Japanese uniparental strains (b, h, n, y) of Meteorus pulchricornis were used in this study (Table 1). They were used in the experiments designed to determine the reaction norms of the response in terms of changes in body colour to the temperature at which the cocoons were kept, and the darkest strain $b$ and lightest strains $\mathrm{y}$ were used in the heat gain experiments. The wet and dry weights of adult females were $3.00 \pm 0.23 \mathrm{mg}$ $($ mean $\pm \mathrm{SD})$ and $1.46 \pm 0.09 \mathrm{mg}$ for strain $\mathrm{b}(\mathrm{N}=5)$, and $2.58 \pm$ $0.15 \mathrm{mg}$ and $1.22 \pm 0.13 \mathrm{mg}$ for strain y $(\mathrm{N}=5)$, respectively.

A culture of each of the four strains was established from a single wild female and all strains were maintained on Spodoptera litura (Fabricius) (Lepidoptera: Noctuidae) larvae as hosts. Adult wasps were reared at $20^{\circ} \mathrm{C}$ under a $16 \mathrm{~L}: 8 \mathrm{D}$ photoperiod and fed cotton wool saturated with a $\sim 50 \%$ (wt $/ \mathrm{vol})$ honey solution. Host larvae were reared on an artificial diet (Insecta LFS, NOSAN) at $25^{\circ} \mathrm{C}$ under a $16 \mathrm{~L}: 8 \mathrm{D}$ photoperiod. The wasps were provided with second instar larvae of the host for oviposition.

The norm of reaction of body colour to the temperatures at which the cocoons are reared

To determine the norms of reaction of body colour of different strains of $M$. pulchricornis to temperature, we kept the cocoons of this parasitoid at a range of constant temperatures. After parasitized host larvae were reared at $25^{\circ} \mathrm{C}$ and under a $16 \mathrm{~L}: 8 \mathrm{D}$ photoperiod, individual cocoons spun by the parasitoid larvae that had emerged from their hosts were immediately put in transparent plastic boxes ( $35 \mathrm{~mm}$ diameter, $20 \mathrm{~mm}$ heigh) and placed in incubators in which the temperature was either 15,20 , 25 or $30^{\circ} \mathrm{C}\left( \pm 2^{\circ} \mathrm{C}\right)$ and the photoperiod $16 \mathrm{~L}: 8 \mathrm{D}$. The relative

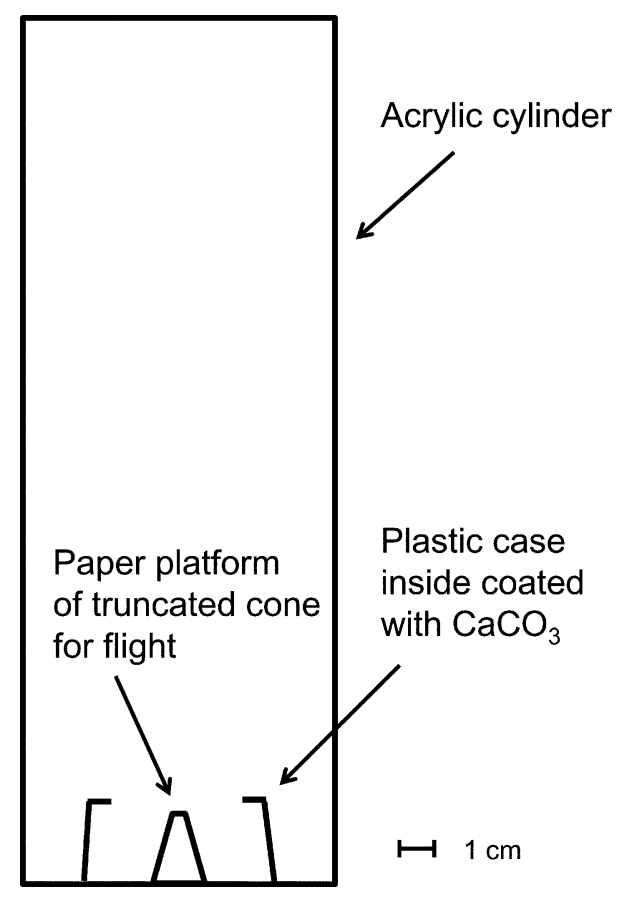

Fig. 1. Flight chamber used to measure the flight activity of adult wasps.

humidity was maintained at $\sim 78 \%$ by means of a saturated $\mathrm{NaCl}$ solution.

Images of the dorsal surfaces of 10 adults (all females) that emerged from the cocoons kept at each temperature were recorded using a digital microscope (VH-8000, KEYENCE). We noticed that the colour of the mesonotum, propodeum and metasomal tergites varied. The darkness of the dorsal sclerites was categorized as either: 0 - totally brownish yellow, 1 brownish yellow with some blackish stains, 2 - dark brown, 3 black with brown portions or 4 - mostly black.

\section{Effect of body colour on body temperature when exposed to solar radiation}

To determine the effect of body colour on the body temperature when exposed to sunshine the temperature of the mesosoma of the lightest (strain y cocoons kept at $25^{\circ} \mathrm{C}$ ) and darkest (strain b cocoons kept at $15^{\circ} \mathrm{C}$ ) wasps were compared (Fig. 2). We used the results for the lightest and darkest wasps to determine the effect of colour on body temperature. Although they belong to different strains, their body size differed only by one-sixth in terms of their dry weight, thus in terms of size they can be regarded as similar. For each replicate, a pair of dried wasps was used to measure the temperature by inserting a $0.15 \mathrm{~mm}$ diameter thermocouple sensor (Extrafine-pointed Temperature Probe $\varphi 0.15 \mathrm{~mm}$, HOGA) into their mesosoma. Mesosomal temperatures in sunshine were recorded every $2 \mathrm{~s}$ for $1000 \mathrm{~s}$ from 11:00-13:00 using a data logger (FUSO-309, FUSO). The

TABLE 1. The four uniparental strains of Meteorus pulchricornis used in this study.

\begin{tabular}{ccccc}
\hline Strain & Original code & Locality & Habitat / host & Collection year and collector \\
\hline b & HYOGO_08_U & Nishinomiya, Hyogo, Honshu & Forest edge / unknown & 2008 by S. Furue \\
h & HIROSHIMA_08_U & Shobara, Hiroshima, Honshu & Forest edge / unknown & 2008 by K. Maeto \\
n & HYOGO_09\#1_U & Nishinomiya, Hyogo, Honshu & Grassland / unknown & 2009 by K. Maeto \\
y & KAGAWA_01_U & Kagawa, Shikoku & Soybean field / Spodoptera litura & 2001by Y. Kunimi ${ }^{1}$ \\
\hline
\end{tabular}

${ }^{1}$ Nguyen et al. (2005) 

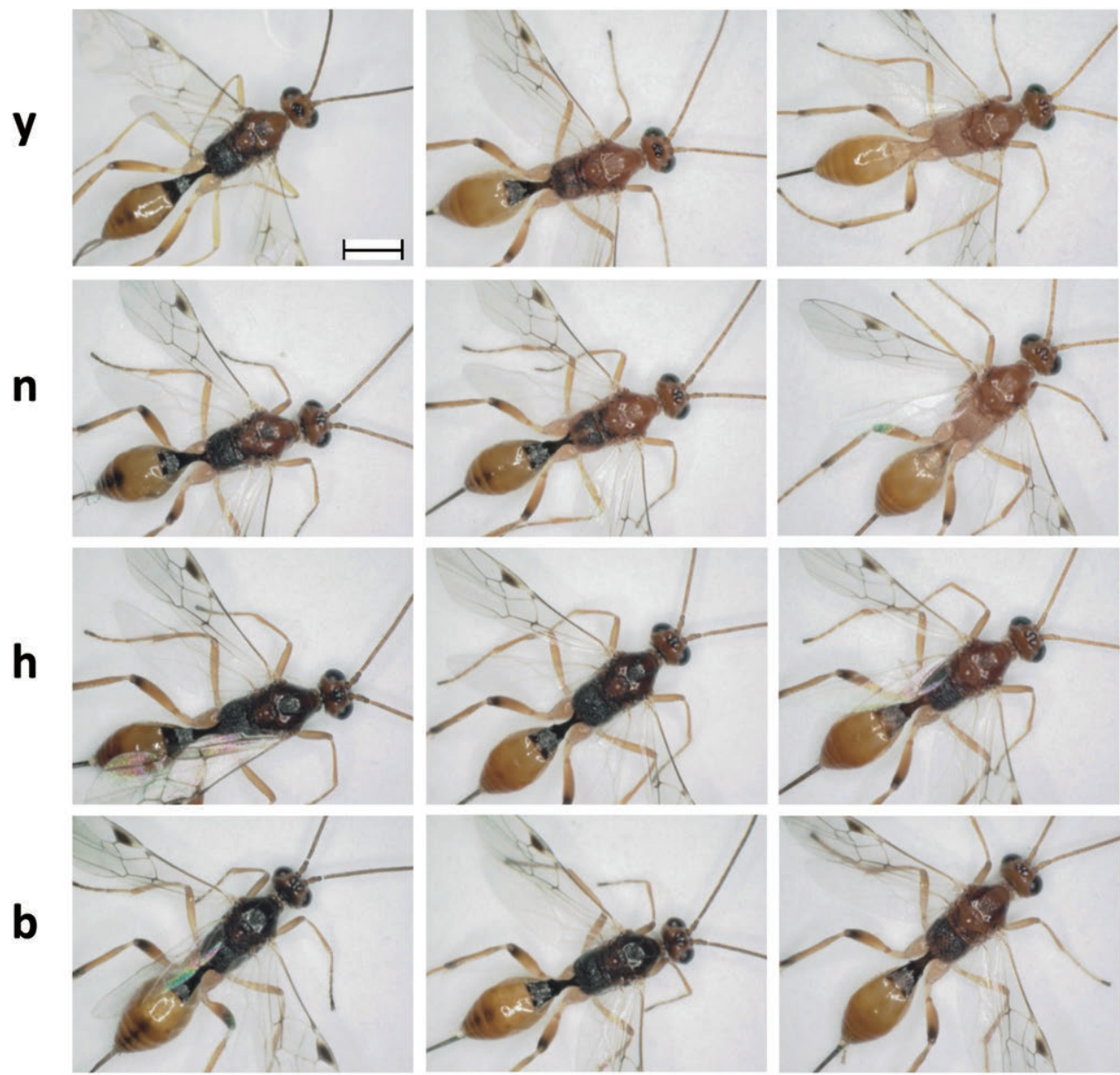

\section{$15^{\circ} \mathrm{C}$}

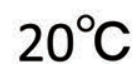

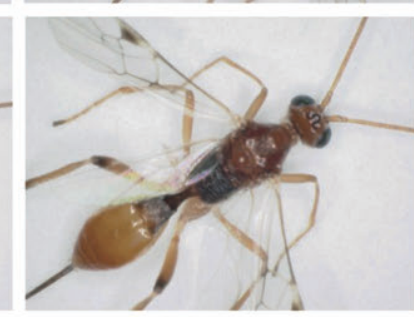

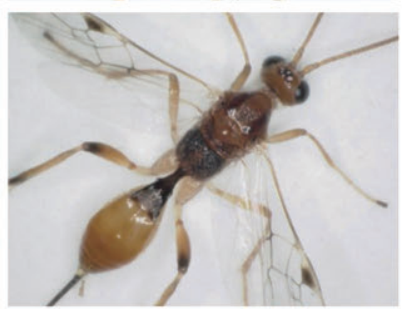

$25^{\circ} \mathrm{C}$
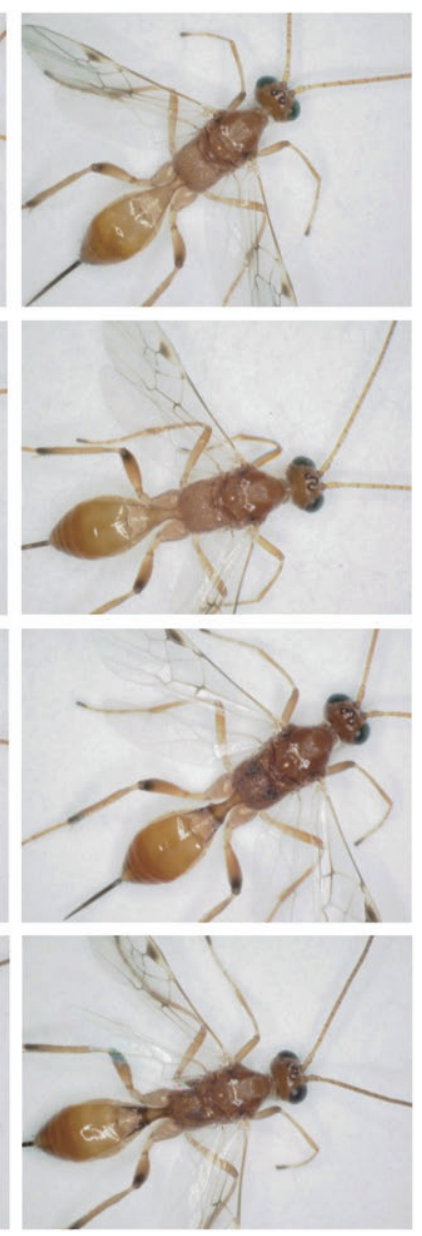

$30^{\circ} \mathrm{C}$

Fig. 2. The dorsal surface of female wasps of four uniparental strains (b, h, n, y) of Meteorus pulchricornis, reared at 15, 20, 25 and $30^{\circ} \mathrm{C}$ during the cocoon stage. Scale bar: $1 \mathrm{~mm}$.

experiments were performed on the campus of Kobe University (lat. $34.7^{\circ} \mathrm{N}$ and long. $135.2^{\circ} \mathrm{E}$, altitude $\sim 200 \mathrm{~m}$ ), Hyogo, Honshu, Japan, on sunny and windless days in mid-February (7 replicates) and mid-May (6 replicates), 2011.

Mesosomal temperatures at the beginning of the experiment and average temperatures recorded over $400-1000 \mathrm{~s}$ periods were compared for the lightest and darkest forms using a paired $t$-test. The $95 \%$ confidence intervals $(95 \% \mathrm{CI})$ of the differences in mesosomal temperature of the two colour forms were estimated based on 1,000 bootstrap samples using IBM SPSS Statistics Version 19.

\section{Effects of body temperature on flight activity}

To determine the body temperature required by wasps for flight, we used a Cox \& Dolder (1995) flight chamber, which consisted of a paper platform in the form of a truncated cone $(0.5 \mathrm{~cm}$ diameter at the top, $2 \mathrm{~cm}$ high), a transparent plastic container (5 cm diameter, $2.5 \mathrm{~cm}$ high) with a hole at the top ( $3.5 \mathrm{~cm}$ diameter) covered by a transparent acrylic cylinder ( 9 $\mathrm{cm}$ diameter, $15 \mathrm{~cm}$ high), which prevented the wasps escaping (Fig. 1). The plastic container was coated inside with powdered $\mathrm{CaCO}_{3}$ to prevent wasps from escaping by walking. To stimulate the wasps to fly cold cathode fluorescent lamps $(5 \mathrm{~W} \times 6$ lamps; 3,000 lux at the platform) were situated $15 \mathrm{~cm}$ above the top of the acryl cylinder.
We used wasps the cocoons of which were reared at $25^{\circ} \mathrm{C}$ and under a $16 \mathrm{~L}: 8 \mathrm{D}$ photoperiod and kept at $20^{\circ} \mathrm{C}$ for $6-13$ days after emergence. They were young enough because the longevity of adult wasps that do not oviposit is over 20 days at $20^{\circ} \mathrm{C}$ (see also Fuester et al., 1993). We placed 10 wasps in the plastic tube for $20 \mathrm{~min}$ and recorded the number that flew. This was repeated five times at $15,18,21,24,27$ and $30^{\circ} \mathrm{C}\left( \pm 1^{\circ} \mathrm{C}\right)$ using wasps of strains $b$ and $y$. The body temperature of the wasps was assumed to be the same as the ambient air temperature. A Generalized Linear Model (logit link, binomial error) was developed using IBM SPSS Statistics Version 19 to test and estimate the effects of strain and temperature on the proportion of wasps that flew.

\section{RESULTS}

\section{Norms of reaction of body colour to the temperature at which the cocoons were kept}

The body colour of all four strains studied darkened with decrease in the temperature at which the cocoon stage was kept, with each strain showing a different relationship between body colour and temperature (Figs 2, 3). Although we examined 10 individuals per condition there was no variation in the colour of individuals of a particular strain recorded at each temperature. The meso- 

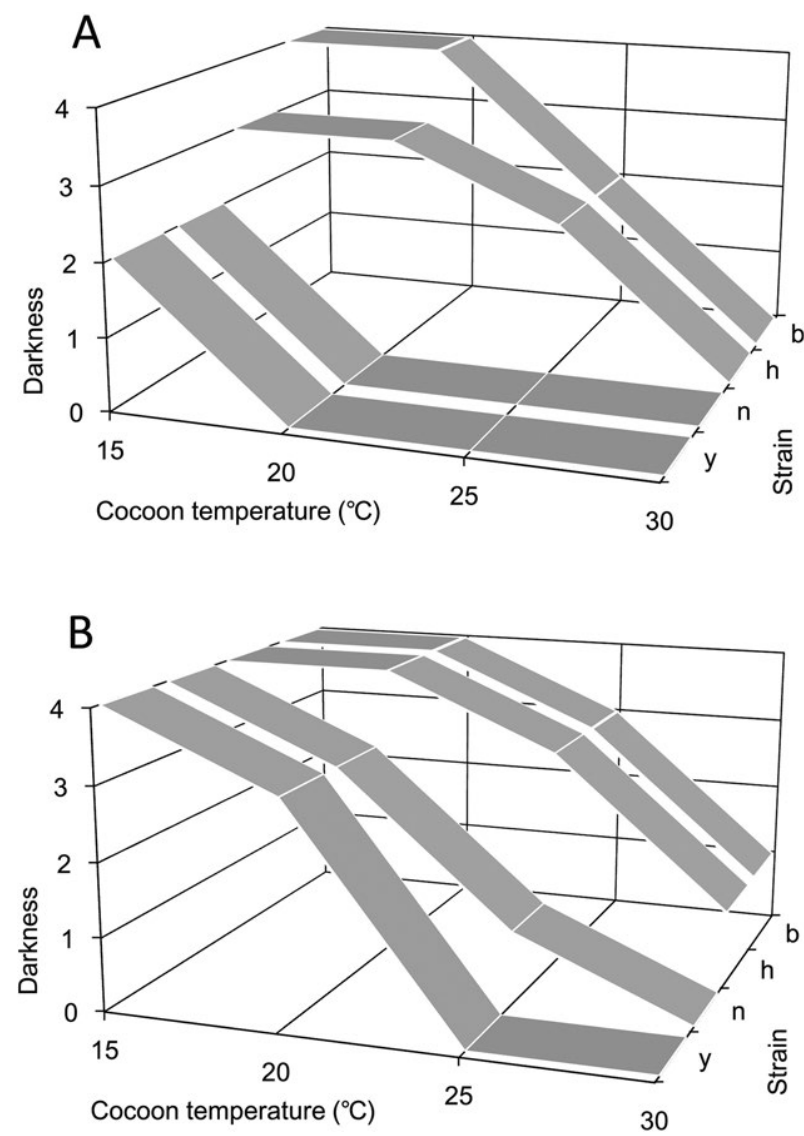

Fig. 3. Norms of reaction in terms of the darkness of the mesonotum (A) and the propodeum and first metasomal tergite (B) of four uniparental strains (b, h, n, y) of Meteorus pulchricornis, reared at $15,20,25$ and $30^{\circ} \mathrm{C}$ during the cocoon stage. The darkness is categorized as either: 0 - totally brownish yellow, 1 - brownish yellow with some blackish stains, 2 - dark brown, 3 - black with brown portions or 4 - mostly black.

notum was invariably brownish yellow (darkness grade 0) at $30^{\circ} \mathrm{C}$ and varied from dark brown (grade 2; strain y) to mostly black (grade 4; strains b) at $15^{\circ} \mathrm{C}$ (Fig. 3a). The propodeum and first metasomal tergite were brownish yellow with some variation (grade $0-1$ ) among strains at $30^{\circ} \mathrm{C}$ and were mostly black (grade 4 ) in all strains at $15^{\circ} \mathrm{C}$ (Fig. 3b). By contrast, the second and following metasomal tergites were mostly brownish yellow irrespective of strain and cocoon temperature, except for the apical tergites, which exhibited some dark staining at lower cocoon temperatures (Fig. 2).

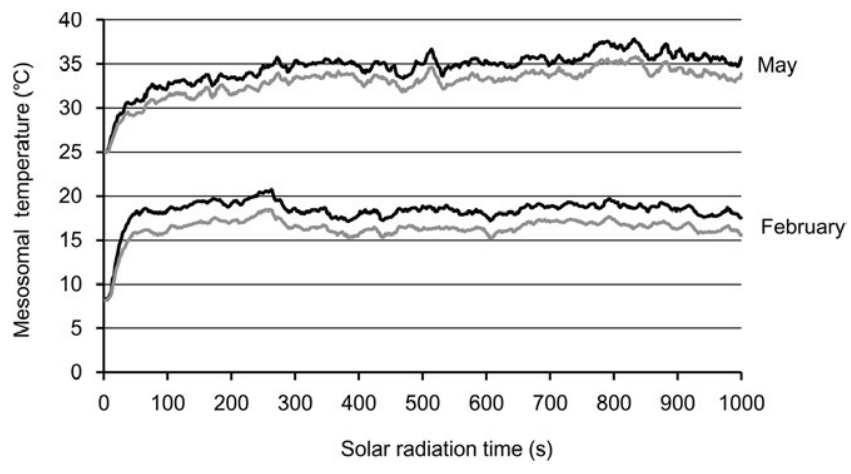

Fig. 4. Mean mesosomal temperature of the lightest (grey lines) and darkest (black lines) dried Meteorus pulchricornis wasps exposed to sunshine in February $(\mathrm{N}=7)$ and May $(\mathrm{N}=$ $6)$.

\section{Effect of body colour on body temperature when exposed to solar radiation}

In sunshine, the mesosomal temperature of both the lightest and darkest wasps reached equilibrium after $\sim 100$ $\mathrm{s}$ in February and $\sim 300 \mathrm{~s}$ in May (Fig. 4). Table 2 shows the range of illumination and the initial (time $=0 \mathrm{~s}$ ) and attained (400-1000 s) mesosomal temperatures of dried wasps in sunshine. The attained temperatures of the lightest and darkest wasps differed significantly in both February and May. The temperature increase was $9.16 \pm$ $2.19^{\circ} \mathrm{C}$ for the lightest and $10.97 \pm 2.40^{\circ} \mathrm{C}$ for the darkest wasp in February, and $8.77 \pm 1.13^{\circ} \mathrm{C}$ for the lightest and $10.51 \pm 1.23^{\circ} \mathrm{C}$ for the darkest wasp in May. The bootstrap estimated $95 \%$ CI of the difference in attained temperatures between the lightest and darkest wasps was $1.6-2.3^{\circ} \mathrm{C}$ in February and $1.1-2.3^{\circ} \mathrm{C}$ in May.

\section{Effects of body temperature on flight activity}

Since the interaction between strain and body temperature was insignificant (Wald chi-square $=0.004$, d.f. $=1$, $P=0.947$ ), the main effects were reanalyzed in its absence. The effects of strain (Wald chi-square $=7.048$, d.f. $=1, P=0.008$ ) and body temperature (Wald chisquare $=152.768$, d.f. $=1, P<0.001)$ on the proportion of wasps that flew were both significant. The proportion of wasps flying steeply increased with increasing ambient temperature in the range 21 to $27^{\circ} \mathrm{C}$ and this increase occurred at lower temperatures in strain $\mathrm{y}$ than strain $\mathrm{b}$ (Fig. 5).

TABLE 2. Mesosomal temperatures of the lightest and darkest Meteorus pulchricornis wasps when exposed to sunshine.

\begin{tabular}{|c|c|c|c|c|c|c|c|}
\hline \multirow[t]{2}{*}{ Month } & \multirow{2}{*}{$\begin{array}{l}\text { Range of illumination } \\
\text { (lux) }\end{array}$} & \multirow{2}{*}{$\begin{array}{l}\text { Time of exposure } \\
\text { to sunshine (s) }\end{array}$} & \multicolumn{3}{|c|}{$\begin{array}{c}\text { Mesosomal temperature }\left({ }^{\circ} \mathrm{C}\right) \\
\text { Mean } \pm \text { SD }\end{array}$} & \multicolumn{2}{|c|}{ Two-tailed paired $t$-test } \\
\hline & & & Lightest wasp $^{1}$ & Darkest wasp ${ }^{2}$ & $\mathrm{~N}$ & $t$ & $P$ \\
\hline \multirow{2}{*}{ February } & \multirow{2}{*}{$61,500-88,200$} & 0 & $8.14 \pm 1.47$ & $8.30 \pm 1.48$ & 7 & 2.42 & 0.052 \\
\hline & & $400-1000$ & $17.31 \pm 1.17$ & $19.27 \pm 1.20$ & 7 & 9.11 & $<0.001$ \\
\hline \multirow{2}{*}{ May } & \multirow{2}{*}{$110,000-135,800$} & 0 & $25.02 \pm 1.41$ & $25.00 \pm 1.41$ & 6 & 0.02 & 0.985 \\
\hline & & $400-1000$ & $33.79 \pm 0.76$ & $35.51 \pm 0.43$ & 6 & 5.26 & 0.003 \\
\hline
\end{tabular}

${ }^{1}$ Adult of strain y of which the cocoons were kept at $25^{\circ} \mathrm{C} ;{ }^{2}$ adult of strain b of which the cocoons were kept at $15^{\circ} \mathrm{C}$. 


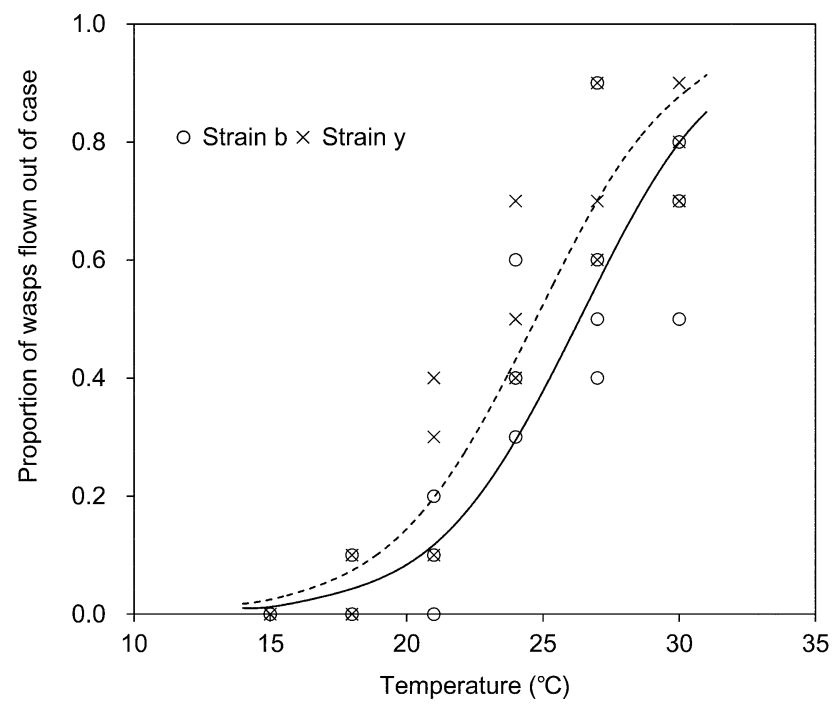

Fig. 5. Proportion of adult Meteorus pulchricornis wasps that flew expressed as a function of ambient temperature. Regression for strain b: logit $\mathrm{y}=-9.878+0.375 \mathrm{x}$ (solid line) and strain $\mathrm{y}$ : $\operatorname{logit} \mathrm{y}=-9.275+0.375 \mathrm{x}$ (broken line).

\section{DISCUSSION}

As shown for other parasitoid wasps in previous studies (e.g. Genieys, 1925; Narayanan et al., 1954), the body colour of adults of $M$. pulchricornis adults darkened when the cocoons were kept at low temperatures. We also revealed that the range in variation in colour differed for different body parts and among uniparental strains. Moreover, we found that this melanism results in an increase in body temperature when they are exposed to sunshine, although its warming effect was at most $\sim 2^{\circ} \mathrm{C}$. This small gain in body temperature could markedly increase the flight activity of wasps at low ambient temperatures.

The order of difference $\left(\sim 2^{\circ} \mathrm{C}\right)$ in the body temperatures of melanic and pale forms exposed to a heat source was the same for a similar sized organism, aphids (Dixon, 1972). Due to the technical difficulty of measuring the body temperature of small living insects, we measured the increase in body temperature of dead wasps exposed to sunshine. Thus, the effects of heat production and evaporative cooling that would occur in living wasps were not considered. Although effects of these physiological functions are not likely to be large in this case because the bodies of the dead wasps were small and dry, they need to be evaluated in order to determine the thermal effects of body colour more precisely.

In early spring or late autumn, when ambient temperatures are low, dark coloured wasps are more likely to be able to fly than light coloured wasps when it is sunny. In contrast, because high body temperature has been shown to have a negative effect on adult survival in a related species Meteorus trachynotus Viereck (Thireau \& Regniere, 1995), being light coloured in summer would presumably be to some extent advantageous in terms of extending longevity. The temperature-dependent melanism observed in this species probably plays a significant role in thermoregulation, with basking during cool conditions. This facultative melanism was most marked in the colour of the mesonotum (covering the flight muscles) and the propodeum and first metasomal tergite (house the muscles of the ovipositor), but that of the following abdominal tergites (covering the reproductive organs) was less marked. Melanism of the middle and apical abdominal tergites is likely to be suppressed in order to avoid detrimental overheating of internal reproductive organs.

The degree of melanism also differed among the parasitoid strains studied. The dark strains $b$ and $h$ may be able to increase body temperature easily in environments with dappled shade such as under tree canopies, since they were collected at the edge of a forest, while the light strains $\mathrm{n}$ and $\mathrm{y}$ originated in grasslands or soybean fields. It must also be noted, however, that the dark strain $b$ exhibited a lower flight activity than the light strain y over a wide range of temperatures (Fig. 5). This might be just coincidental, but some trade-off between melanism and alternative tactics should be taken into account (Talloen et al., 2004; Clusella-Trullas et al., 2007). For example, the greater flight ability of strain y compared to strain $\mathrm{b}$ might be because strain y can produce more heat by shivering its thoracic muscles (Heinrich, 1993). Although the daily activity of the different strains is unknown, shivering may be superior to melanism in terms of increasing flight activity for the light strain y, if it is more nocturnal than the dark strain $b$.

This study shows that variation in body colour in $M$. pulchricornis reflects the ambient temperatures at which the cocoon stage was kept and facilitates adaptation to changing thermal environments, providing the first evidence in support of the thermal melanism hypothesis in parasitoid wasps, although the ecological significance of the difference among strains remains unexplained. Variation in the body colour of parasitoids should be considered in biological control programs that seek to use them because of its indirect effects on adult activity via body temperature.

ACKNOWLEDGEMENTS. We would like to thank Y. Kunimi, M. Nakai and S. Furue for providing the parasitoid strains used in this study. Collection of the darkest strain of parasitoids by $\mathrm{S}$. Furue enabled completion of this research. This research was in part supported by JSPS KAKENHI Grant Number 19380036, 25292034

\section{REFERENCES}

Barbosa P. \& Frongillo JR. E.A. 1977: Influence of light intensity and temperature on the locomotory and flight activity of Brachymeria intermedia [Hym.: Chalcididae] a pupal parasitoid of the gypsy moth. - Entomophaga 22: 405-411.

Bernardo U., Pedata P.A. \& Viggiani G. 2007: Phenotypic plasticity of pigmentation and morphometric traits in Pnigalio soemius (Hymenoptera: Eulophidae). - Bull. Entomol. Res. 97: 101-109.

Berry J.A. \& Walker G.P. 2004: Meteorus pulchricornis (Wesmael) (Hymenoptera: Braconidae: Euphorinae): an exotic polyphagous parasitoid in New Zealand. - N. Z. J. Zool. 31: 33-44. 
BRAKEFIELD P.M. 1984: Ecological studies on the polymorphic ladybird Adalia bipunctata in the Netherlands. II. Population dynamics, differential timing of reproduction and thermal melanism. - J. Anim. Ecol. 53: 775-790.

Brakefield P.M. \& Willmer P.G. 1985: The basis of thermal melanism in the ladybird Adalia bipunctata: differences in reflectance and thermal properties between the morphs. Heredity 54: 9-14.

Clusella-Trullas S., van Wyk J.H. \& Spotila J.R. 2007: Thermal melanism in ectotherms. - J. Thermal Biol. 32: $235-245$.

Clusella-Trullas S., Terblanche J.S., Blackburn T.M. \& Chown S.L. 2008: Testing the thermal melanism hypothesis: a macrophysiological approach. - Funct. Ecol. 22: 232-238.

Cox P.D. \& Dolder H.S. 1995: A simple flight chamber to determine flight activity in small insects. - J. Stored Prod. Res. 31: 311-316.

Cox P.D., Wakefield M.E. \& JACoB T.A. 2007: The effects of temperature on flight initiation in a range of moths, beetles and parasitoids associated with stored products. - J. Stored Prod. Res. 43: 111-117.

De Jong P.W., Gussekloo S.W.S. \& Brakefield P.M. 1996: Differences in thermal balance, body temperature and activity between non-melanic and melanic two-spot ladybird beetles (Adalia bipunctata) under controlled conditions. - J. Exp. Biol. 199: 2655-2666.

DiXoN A.F.G. 1972: Control and significance of the seasonal development of colour forms in the sycamore aphid, Drepanosiphum platanoides (Schr). - J. Anim. Ecol. 41: 689-697.

Forsman A. 1997: Thermal capacity of different colour morphs in the pigmy grasshopper Tetrix subulata. - Ann. Zool. Fenn. 34: 145-149.

Fuester R.W., Taylor P.B., Peng H. \& Swan K. 1993: Laboratory biology of a uniparental strain of Meteorus pulchricornis (Hymenoptera: Braconidae), an exotic larval parasite of the gypsy moth (Lepidoptera: Lymantriidae). - Ann. Entomol. Soc. Am. 86: 298-304.

Genieys P. 1925: Habrobracon brevicornis Wesm. - Ann. Entomol. Soc. Am. 18: 143-202.

HeInRICH B. 1993: The Hot-Blooded Insects: Strategies and Mechanisms of Thermoregulation. Harvard University Press, Cambridge, MA, $601 \mathrm{pp}$.

HuddeEston T. 1980: A revision of the western Palaearctic species of the genus Meteorus (Hymenoptera: Braconidae). Bull. Br. Mus. (Nat. Hist.) (Entomol.) 41: 1-58.

KINGSOLVER J.G. 1987: Evolution and coadaptation of thermoregulatory behavior and wing pigmentation pattern in pierid butterflies. - Evolution 41: 472-490.

KINGSOLVER J.G. 1995: Fitness consequences of seasonal polyphenism in western white butterflies. - Evolution 49: 942-954.

LIU Y. \& Li B. 2006: Developmental interactions between Spodoptera exigua (Noctotuidae: Lepidoptera) and its unparental endoparasitoid, Meteorus pulchricornis (Braconidae: Hymenoptera). - Biol. Control 38: 264-269.

Maeto K. 1989: Systematic studies on the tribe Meteorini (Hymenoptera, Braconidae) from Japan: V. The pulchricornis group of the genus Meteorus (1). - Jpn. J. Entomol. 57: 581-595.

Narayanan E.S., Angalet G.W., Subba Rao B.R. \& D’Souza G.I. 1954: Effect of refrigeration of the pupae of Microbracon brevicornis Wesm. on the pigmentation of the adult. Nature 173: 503-504.

Nguyen D.H., Nakai M., Takatsuka J., OKuno S., Ishit T. \& KUNIMI Y. 2005: Interaction between a nucleopolyhedrovirus and the braconid parasitoid Meteorus pulchricornis (Hymenoptera: Braconidae) in the larvae of Spodoptera litura (Lepidoptera: Noctuidae). - Appl. Entomol. Zool. 40: 325-334.

Quicke D.L.J. 1997: Parasitic Wasps. Chapman \& Hall, London, $470 \mathrm{pp}$.

Shu-Sheng L. \& CARver M. 1982: The effect of temperature on the adult integumental coloration of Aphidius smithi. - Entomol. Exp. Appl. 32: 54-60.

SteVenson R.D. 1985a: Body size and limits to the daily range of body temperature in terrestrial ectotherms. - Am. Nat. 125: $102-117$.

SteVENSON R.D. 1985b: The relative importance of behavioral and physiological adjustments controlling body temperature in terrestrial ectotherms. - Am. Nat. 126: 362-386.

TAKashino K., Kobayashi H. \& OKada T. 1998: Research for parasitic natural enemies to larvae of two Helicoverpa species in Shikoku. - Proc. Assoc. Plant Prot. Shikoku 33: 49-55 [in Japanese].

Talloen W., Van Dyck H. \& Lens L. 2004: The cost of melanization: butterfly wing coloration under environmental stress. - Evolution 58: 360-366.

Thireau J.C. \& Regniere J. 1995: Development, reproduction, voltinism and host synchrony of Meteorus trachynotus with its hosts Choristoneura fumiferana and C. rosaceana. Entomol. Exp. Appl. 76: 67-82.

TRUE J.R. 2003: Insect melanism: the molecules matter. Trends Ecol. Evol. 18: 640-647.

VAN Dyck H. \& MatThysen E. 1998: Thermoregulatory differences between phenotypes in the speckled wood butterfly: hot perchers and cold patrollers? - Oecologia 113: 326-334.

VAN DYCK H. \& WIKLUND C. 2002: Seasonal butterfly design: morphological plasticity among there developmental pathways relative to sex, flight and thermoregulation. - J. Evol. Biol. 15: 216-225.

WatT W.B. 1968: Adaptive significance of pigment polymorphisms in Colias butterflies. I. Variation of melanin pigment in relation to thermoregulation. - Evolution 22: 437-458.

Yамамото M., Chau N.N.B. \& Maeto K. 2009: Host movement initiates oviposition behavior of Meteorus pulchricornis, a braconid parasitoid of free-living lepidopteran larvae. Appl. Entomol. Zool. 44: 53-59.

Recived March 12, 2013; revised and accepted April 15, 2013 